\title{
1. Advancing empirical research on organizational routines: introduction $^{1}$
}

\author{
Markus C. Becker and Nathalie Lazaric
}

Since the concept of organizational routines was popularized by Nelson and Winter (1982), its potential to understand organizations and organizational change has attracted scholars' attention. Organizational routines hold one of the keys to understanding how organizations accomplish their tasks, how they change, and how organizational capabilities are accumulated, transferred and applied (Cohen et al., 1996; Winter, 2000). Most of the potential of the concept of organizational routines to contribute to understanding organizations and how they change is still untapped, however. The last years, though, have seen increased empirical research that applies the concept of organizational routines in understanding organizations. Furthermore, different methodologies for empirical research on organizational routines have also been pioneered, described and tested recently. Results of empirical studies employing these methodologies are starting to accumulate. The present volume collects a number of empirical contributions that apply the concept of organization routines for casting light on organizational phenomena. It showcases the state of the art in empirical research on organizations which employs the concept of organizational routines in understanding organizations. This volume follows up on the special section 'Towards an operationalization of the routines concept' in Industrial and Corporate Change, 14(5). ${ }^{2}$ Consulting that section and the present volume will show how the chapters in this volume tackle some of the challenges in applying organizational routines in analysing organizations that were described in the special section (Becker et al., 2005). We leave it to readers to judge how far empirical research applying the concept of organizational routines has already come in realizing the potential of the organizational routines concept to understanding organizations. The present volume is a display of the fact, however, that such research is moving forward, and that issues of empirical research on routines are currently being tackled. In the remainder of this introductory 
chapter, we sketch briefly which issues the chapters speak to, and how they are connected. We then conclude by a brief outlook on further empirical research on organizational routines.

The two chapters in Part I provide different perspectives on the conceptual foundations of the routines concept. Richard Nelson provides a perspective on organizational routines that emphasizes routines as 'technologies', that is, productive techniques for doing something. In a 'physical technology', physical inputs, apparatus and procedures employing these, largely control what is done, with the organizational aspects perhaps complex but largely derivative of the technology. In a 'social technology', on the other hand, human interactions are the dominant part of the story, with the physical aspects of the technology relatively simple. As Nelson explains in his chapter, the operation of organizational routines tends to involve both physical and social technologies. Organizational capabilities involve both its 'engineering' strength, in the sense of command of the physical technologies it needs to operate, and its strength in management and ability to coordinate the various activities it needs to employ to be effective. Taking such a perspective allows asking fruitful research questions, such as how and why a routine works as it does, how routines evolve, and what the role of interaction is between social and physical technologies. Chapters such as the ones by Luciana D'Adderio and Brian Pentland, Thorvald Haerem and Derek Hillison are consistent with such a view and provide illustration of it. In his chapter, Geoffrey Hodgson proposes a perspective on organizational routines that sees them as dispositions to energize conditional patterns of behaviour within an organized group of individuals, involving sequential responses to cues. Such a perspective helps distinguish organizational routines from individual habits. Routines are structures of interlocking individual habits, and thus more than mere aggregations of individual-level habits. The chapter also discusses how routines act as repositories of knowledge and how they replicate.

One of the key promises of the organizational routines concept is to provide a means of describing organizational behaviour and how it changes. To have an empirical science of organizational routines, however, we need to be able to identify particular routines and compare them to other routines. There are two issues that need to be tackled in order to advance here. Few quantitative methods are available for unpacking the structure and evolution of routines. Moreover, which data should be used for such an exercise? As to the first issue, one of the most promising methods so far is event-sequence analysis, pioneered by Brian Pentland. The two chapters in Part II represent an introduction to the method. They go beyond a simple introduction, however. They also provide two specific examples of how it can be applied, and what insights are to be garnered by applying 
it. Carlo Salvato's chapter offers a step-by-step guide of how to apply the method, while Pentland, Haerem and Hillison offer a particularly careful and comprehensive overview of techniques for analysing and representing the structure of organizational routines, and a discussion of the methodological and practical issues involved in such a method. As to the problem of data, the two chapters show how workflow event logs (Pentland, Haerem and Hillison) and archival material on organizational processes (Salvato) can be used to analyse organizational routines. The chapters illustrate these techniques using over 2000 performances of an invoice approval routine, as captured in a workflow management system (Pentland, Haerem and Hillison), and archival data on development processes of 90 products initiated by Alessi, the design firm (Salvato). These two chapters provide a great opportunity for advancing the possibility of drawing on empirical research on routines to cast light on issues such as the impact of rules and procedures on behaviour patterns (see D'Adderio, Becker and Zirpoli, and van der Steen in this volume), how to select the appropriate level of granularity for describing routines, and how to advance our understanding of routine combinatorics, one of the basic ways in which organizations evolve (Becker et al., 2006). Rik Wenting's chapter focuses on describing a different aspect, that is, the replication of routines. He studies the transfer of organizational routines from parent firms to their spin-off companies in the fashion industry from its inception in 1858 to today. Drawing on a unique dataset of the fashion design industry covering 554 biographies of the world's top fashion designers, Wenting traces inheritance back to all previous employers of the entrepreneur, constituting a complete genealogical graph. He then tests whether quantity or quality of pre-entry experiences of the founder affected firm survival. His article makes a contribution on methods to study the replication of routines. It also casts light on the effects of routine replication, which he studies over an unusually long time horizon.

We just mentioned how empirical research on organizational routines can advance our understanding of routine replication and routine combinatorics, and thus, organizational evolution. The chapters also inform two other fundamental questions that organizational routines can cast light on; the sources of stability and change in organizations.

The chapters in Part III contribute to understanding stability in organizations by analysing organizational routines. Jeremy Birnholtz, Michael Cohen and Susannah Hoch present a qualitative case study that analyses sources of stability in organizations that lie dormant for substantial periods and are regenerated after such dormant periods. What are the sources of stability that make such organizations recognizably 'the same'? Summer camps provide a unique environment for exploring these issues because they lie dormant for much of the year until their members come together to bring 
the organization 'back to life', where the result of this regeneration process is recognizably another instance of 'the same' organization to repeat clientele. The chapter also informs the question regarding how we can refer to a routine as 'the same' entity, even when there are substantial differences in different specific instances. It also represents one of the few empirical articles that shed light on how to identify dispositions, and how such mutually adapted action dispositions have an impact by forming a coherent system. The chapter by Martijn van der Steen focuses on rules as sources of stability in behaviour patterns. Analysing the case of a change initiative at Rabobank, he investigates the interaction between the formal rules as embedded in the accounting and controlling system, and behaviour patterns. His chapter contributes to understanding under which conditions such interaction contributes to inertia, and under which circumstances it contributes to organizational change. The chapter also casts light on the impact of incentives and management tools on the interaction between rules and action patterns (cf. the chapters by D'Adderio and Becker and Zirpoli in this volume).

Part IV groups chapters that cast light on organizational routines as drivers of organizational change and novelty. In her chapter, Luciana D'Adderio builds on recent advances in Routines and Performativity Theory to provide a nuanced characterization of the key influence of artefacts and agencies on the change and stability of routines. Ultimately, in this framework, a routine's stable pattern emerges out of a double recursive loop of convergence and divergence between procedure and performances and the competitive organizational arrangements in which the routine is stabilized. Drawing from the ethnographical observation of the 'freeze' routine at a leading automotive manufacturer, this chapter thus shows how some organizational agencies are able to inscribe their abstract views of the routine in artefacts (that is SOPs, rules) and tools (that is software), thus creating stronger agencements. These heterogeneous agentic programmes, being deeply embedded in a thick web of organizational relationships, are more difficult to oppose and thus can 'turn exceptions into rules'. The balance between stabilization and destabilization is not, therefore, the result of the interplay between structures, on one side, and agencies, on the other, but the outcome of the struggles among competing performative programmes. The stability resulting from performative struggles is similar to Nelson and Winter's (1982) notion of 'truce' as a continuously challenged and emergent achievement; this framework, however, captures the direction, intensity and persistence of the forces that are responsible for stabilizing or destabilizing the routine. The chapter by Markus Becker and Francesco Zirpoli investigates the role of stable behaviour patterns and of standard operating procedures that can contribute to the stability of behaviour patterns in innovation processes. They start from the observation that 
procedures and stable behaviour patterns for accomplishing innovation tasks have very prominent roles in the new product development management literature, and that many innovating firms have many such rules and procedures and carry out innovation in routinized ways. This also includes examples of radical innovation, such as at IDEO, the design firm. Following this lead, they ask 'what is the role, if any, of standard operating procedures and stable behaviour patterns in repeatedly generating innovations?' The question is pursued with a case study of the use of virtual simulation technology at the Engineering Center of a major European car manufacturer. Frédéric Huet and Nathalie Lazaric focus on the organizational conservatism of firms and the reluctance to regenerate their knowledge base. In their chapter, they explain why firms are reluctant to change their organizational routines. By discussing the notion of transactions and cooperation, they identify diverse 'routine transactions' which are related to habitual activities involving stabilized knowledge, and 'strategic transactions' related to situations of novelty implying new opportunities and for which there is no stabilized knowledge. This terminology, developed by Commons (1950), is applied in explaining organizational conservatism in a population of SMEs which are pushed to innovate to survive in hostile environments but are reluctant to do so, because implementing the creation of novel routines implies a revision of their representations (that is their beliefs or their taken-for-granted assumptions).

So far, we have briefly described what questions the chapters tackle, and what contributions they make to these questions. In so doing, the chapters also push the frontier by identifying new questions that can guide further research.

\section{QUESTIONS ON METHODS}

What level of granularity to select for describing routines is a critical methodological issue. How do we select a level of granularity that assures we describe organizational routines that are meaningful (Becker et al., 2005)? Recent empirical research has marshalled econometric measures for coping with the task of describing organizational variation present in routines, such as variety in how tasks are accomplished (Pentland, Haerem and Hillison), in the content of interactions between firms (Huet and Lazaric), or of antecedents of the actual routines (Wenting). All these measures present progress regarding our ability to describe and identify organizational variation. Because such methods are now available, and describing and identifying organizational variation has become possible, how to decide on the appropriate level of granularity for such a description has become even 
more important than before. As analytical methods have become available, we might want to scrutinize them for whether they have an in-built bias for particular levels of granularity (either in the method itself or in the data that is available to be analysed with a particular method).

\section{QUESTIONS ON STABILITY AND CHANGE}

The chapters have taken three different perspectives for understanding the stability or change of behaviour patterns for achieving organizational tasks: routine combinatorics, replication, and rules and standard operating procedures as sources of stability or change. In each, they have not just added to our understanding but have also flagged new questions that can guide further research. Regarding rules and standard operating procedures, some authors in this volume and in the literature more generally are inspired by the dialectics and recursive interaction between the description of behaviour (ostensive) and the behaviour itself (performative) (Feldman and Pentland, 2003). It appears that much current empirical research is exploring this line of inquiry. One important impulse provided by Feldman and Pentland (2003) was to emphasize that rules and operating procedures do not always have just a stabilizing effect on behaviour patterns. Rather, under certain conditions they can also lead to endogenous organizational change or to novel outcomes of organizational processes. Identifying such conditions would appear a natural next step in this line of inquiry. As for routine combinatorics, describing the building blocks that are recombined seems to be the next issue that needs to be solved. Deciding on what are meaningful levels of granularity is obviously important here. Once the building blocks are identified, identifying the mechanisms of recombination is high on the research agenda. As Hodgson argued in his chapter, stable behaviour patterns are emergent properties of generative structures. Regarding replication, an important item on the research agenda is therefore to describe the replication of these generative structures that generate stable behaviour patterns, not of the behaviour patterns themselves. The generative structures are difficult to observe, yet hold the key to understanding the replication of stable behaviour patterns. Wenting's chapter does a nice job in focusing on such generative structures as the object of replication, rather than specific behaviour patterns. Another issue put on the research agenda by Wenting's chapter and other emergent research is the role of space in replication. While economic geography has long insisted on proximity as an important variable explaining the results of replication processes, integrating space in models of the replication of organizational routines is still an unaccomplished task. 
In conclusion, the chapters in the present volume offer insights from empirical research that show how the organizational routines concept can advance our understanding of organizations and how they change. Much still remains to be done. The volume provides evidence, however, that empirical research employing the organizational routines concept in analysing organizations is under way and has increased over the last few years. Importantly, such empirical research also starts to be more cumulative as it begins to follow the same lines of inquiry and to use the same methods. These are all hallmarks of an advancing field.

\section{NOTES}

1. The work on this volume has benefited from a research grant from the Agence Nationale de Recherche (ANR) under the 'Jeunes Chercheuses et Jeunes Chercheurs' programme (grant no. JC05_44029).

2. It also provides a companion to the Handbook of Organizational Routines (Becker, 2008).

\section{REFERENCES}

Becker, Markus C. (ed.) (2008), Handbook of Organizational Routines, Cheltenham, UK and Northampton, MA, USA: Edward Elgar.

Becker, Markus C., Thorbjørn Knudsen and James G. March (2006), 'Schumpeter, Winter, and the sources of novelty', Industrial and Corporate Change, 15(2), 353-71.

Becker, Markus C., Nathalie Lazaric, Richard R. Nelson and Sidney G. Winter (2005), 'Applying organizational routines in analyzing organizations', Industrial and Corporate Change, 14(5), 775-91.

Cohen, Michael D., Roger Burkhart, Giovanni Dosi, Massimo Egidi, Luigi Marengo, Massimo Warglien and Sidney G. Winter (1996), 'Routines and other recurring action patterns of organizations: contemporary research issues', Industrial and Corporate Change, 5(3), 653-98.

Commons, J.R. (1950), The Economics of Collective Action, Madison, WI: University of Wisconsin Press.

Feldman, M.S. and B.T. Pentland (2003), 'Reconceptualizing organizational routines as a source of flexibility and change', Administrative Science Quarterly, 48, 94-118.

Nelson, Richard R. and Sidney G. Winter (1982), An Evolutionary Theory of Economic Change, Cambridge, MA: Belknap Press of Harvard University Press.

Winter, Sidney G. (2000), 'The satisficing principle in capability learning', Strategic Management Journal, 21, 981-96. 
Markus C. Becker and Nathalie Lazaric - 9781848447240 Downloaded from PubFactory at 04/26/2023 01:24:18PM 